\title{
The Traceability System Design Based On The HACCP
}

\author{
Yu-Hui-Li, Shuai Yang , Bo Li, You-Fen Zhang \\ Faculty of Information Engineering and Automation, Kunming University of Science and Technology, \\ Kunming 650500, China \\ E-mail: 1484946977@qq.com, 1242763560@qq.com, lbly9177@163.com, 573921041@qq.com
}

\begin{abstract}
With the rapid development of food safety business, people on food production visualization traceability requirements are getting higher and higher. This thesis aims at analyzing on livestock traceability management and livestock supply chain processes. Based on HACCP principles and methods, we analyze the key node of each supply chain; build livestock traceability chain key node information, design livestock traceability processes and systems functions, to achieve information collaboration and sharing.
\end{abstract}

Keywords-livestock traceability; food safety; HACCP; functional framework

\section{INTRODUCTION}

Food safety is a serious threat to people's health and causes great economic losses to consumers and food related industries, so more and more people's pay attention to it. Animal products are the most important kind food. Because the food chain is longer than other food chain, the information supervision and management of animal products is difficult to achieve in whole process, the safety of animal products is particularly prominent. Therefore, it is of great practical significance to carry out the research on the safety of animal production, and establish the traceability system of animal products.

\section{LIVESTOCK TRACEABILITY SYSTEM ANALYSIS}

\section{A. Animal Products Traceability System.}

Livestock products traceability system achieve the full monitoring of food and products information transparent framework from production to sales throughout the supply chain, to ensure product quality and safety by collecting and processing quality and safety information on food production, processing, transportation, consumer[1].

\section{B. Animal Products Supply Chain.}

The livestock product supply chain involves the breeding, slaughter, transportation, storage and sale of animals, as shown in fig. 1.

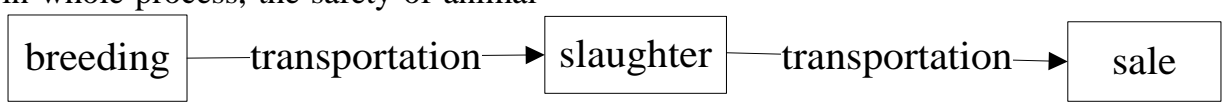

Figure 1. The supply chain of animal products.

Breed aquatics, in the source of the information, is not only the initial link of the livestock products supply chain, but also the longest time in the whole supply chain link. In order to ensure meat quality and improve the safety level of the most basic link, the scale of farms must follow the national GMP (a prerequisite for ensuring food safety in production) [2]. Next link is the slaughter link. For livestock slaughtering enterprises, the main responsibility is slaughter and carcass segmentation of livestock (primary processing). Sales links, in the end of the supply chain of animal products, are closely related to consumers. In order to ensure meat information integrity and traceability system availability, it should provide fully trusted meat information and simple traceability means for consumers, which directly affects the enterprise's brand image and consumer's purchase desire. At the same time, it is also a phase by which consumers get detailed information through the code and complete tracing.

\section{Livestock Traceability Process.}

The Traceability process refers to propose request and respond to tracing requests. By active RFID technology and bar code technology, livestock information and information systems achieve non-contact interaction, fundamentally erecting a bridge between the material world and the world of information, so that the material world and the world of information can be quickly and efficiently converted, processed and be traced back [7]. Any traceability participating parties may make a request for traceability, customer complaints can be used as a source of request and the reasons for the recall of defective products. The specific process is shown in fig. 2 .

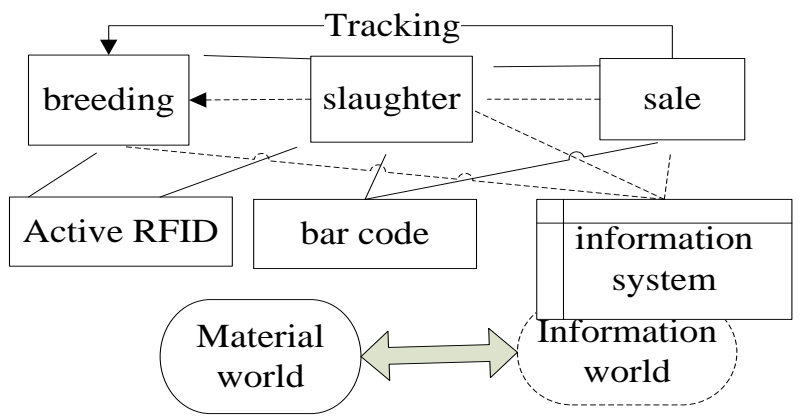

Figure 2. Traceability process of animal products.

On the query system, Consumers can directly query the information on the quality and safety of livestock product through animal products, leaving some slaughtering 
segmentation bar code identification, or report animal products quality and safety problems to the relevant departments. When the problem of the quality and safety of animal products appear, people can find the whole process of the problem through the traceability system. Livestock producers in the traceability system collect information, save the file of livestock products, and norms market of livestock products with livestock products safety supervision department, which really protect consumer interests.

\section{HACCP SYSTEM ANALYSIS}

HACCP system, based on the GMP (from animal breeding, slaughtering, transport and sales link specific specification) and SSOP (hygienic standard for the specific operation of the foundation), ensure the health and safety of food by controlling the potential hazards $[3,4]$. HACCP is concerned about the impact of food hygiene and safety of CCP (critical control point), to play a multiplier effect through the analysis of the harm of CCP and prevention.The implementation of the HACCP system includes 12 links [5].

Taking China's pork production and processing for example, we get analysis that pig breeding link key points include: drug procurement, procurement of feed, farm building, quarantine, pens cleaning and disinfection, isolation treatment and dead cat treatment. The key points of transport links include: pre transport quarantine, pig transport vehicles disinfection, pork quarantine and pork transport vehicle disinfection. The key points of the slaughter process include the inspection of the two cards, pre slaughter quarantine, spraying, etc. The key point of the sales link is the quarantine receipt [6]. The key points in the supply chain of animal products, as shown in fig. 3.

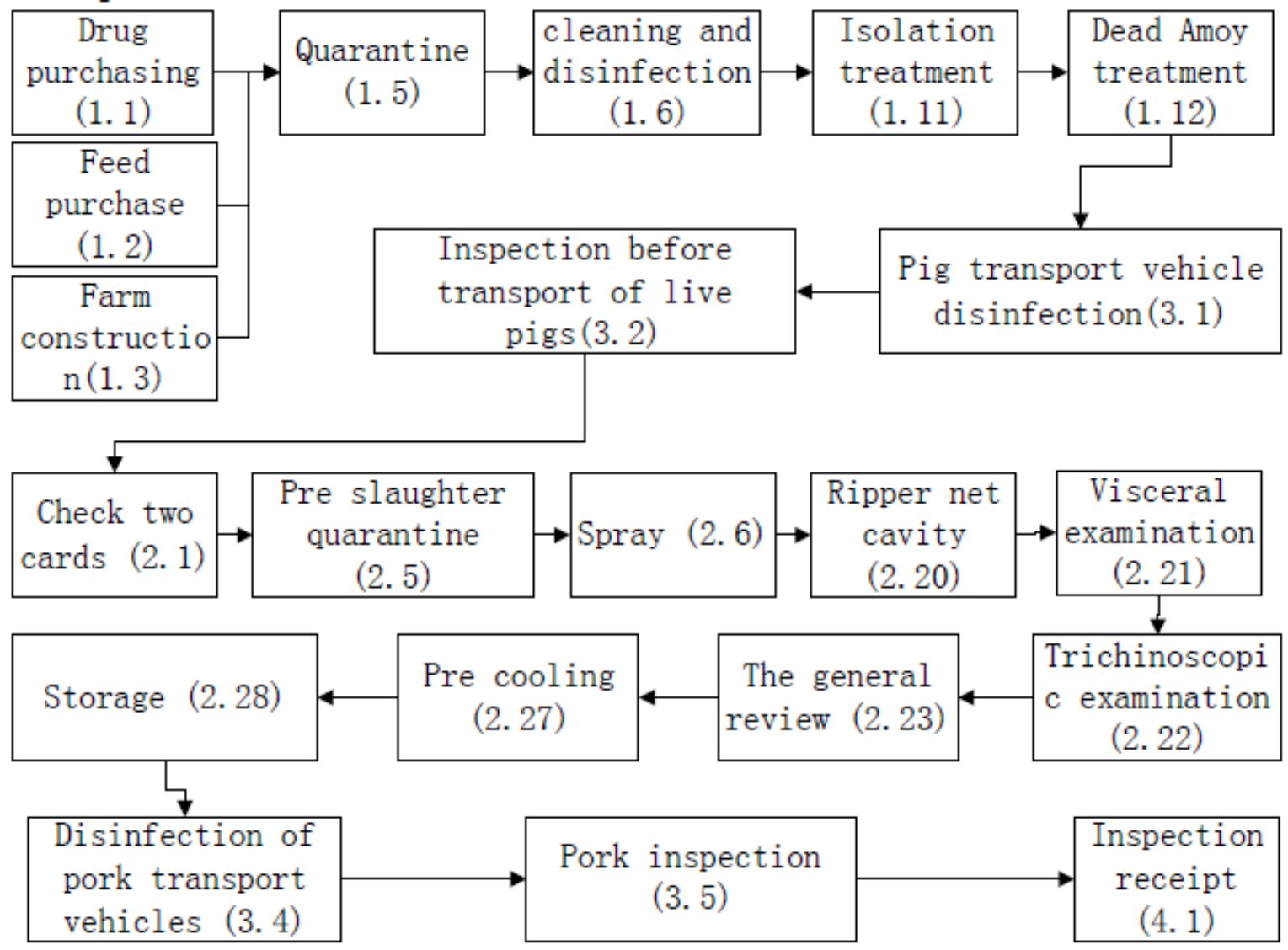

Figure 3. Key points in the supply chain of animal products.

IV. THE GOAL AND FUNCTION OF THE SYSTEM

The target of traceability system of livestock products can sum up as follow: the source can be traced back, production (processing) has a record, the flow can be tracked, information can be queried, product can be recalled, and the responsibility can be investigated. Among them, in the first, three are the functional requirements of the traceability system for livestock products, the later three sentences are the target of the traceability system of animal products. The function and target of the traceability system of the livestock product is shown in fig. 4. 


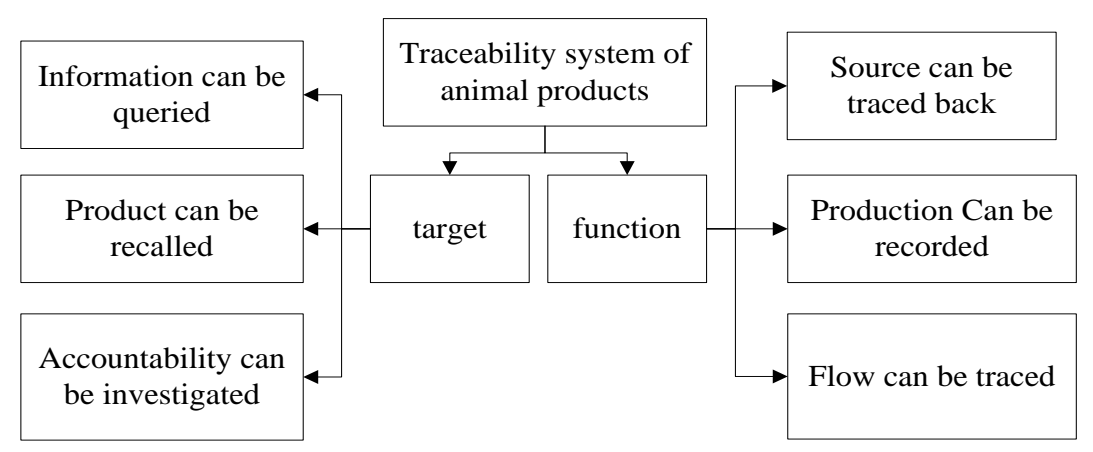

Figure 4. Objective and function of the traceability system of animal products.

In the System, information can be queried with a variety of channels including web site, telephone, SMS, touch screen placed in the store, as well as mobile traceability terminal.

\section{DESIGN OF TRACEABILITY SYSTEM FOR LIVESTOCK PRODUCTS}

\section{A. Overall System Architecture}

The traceability system of animal products can fully

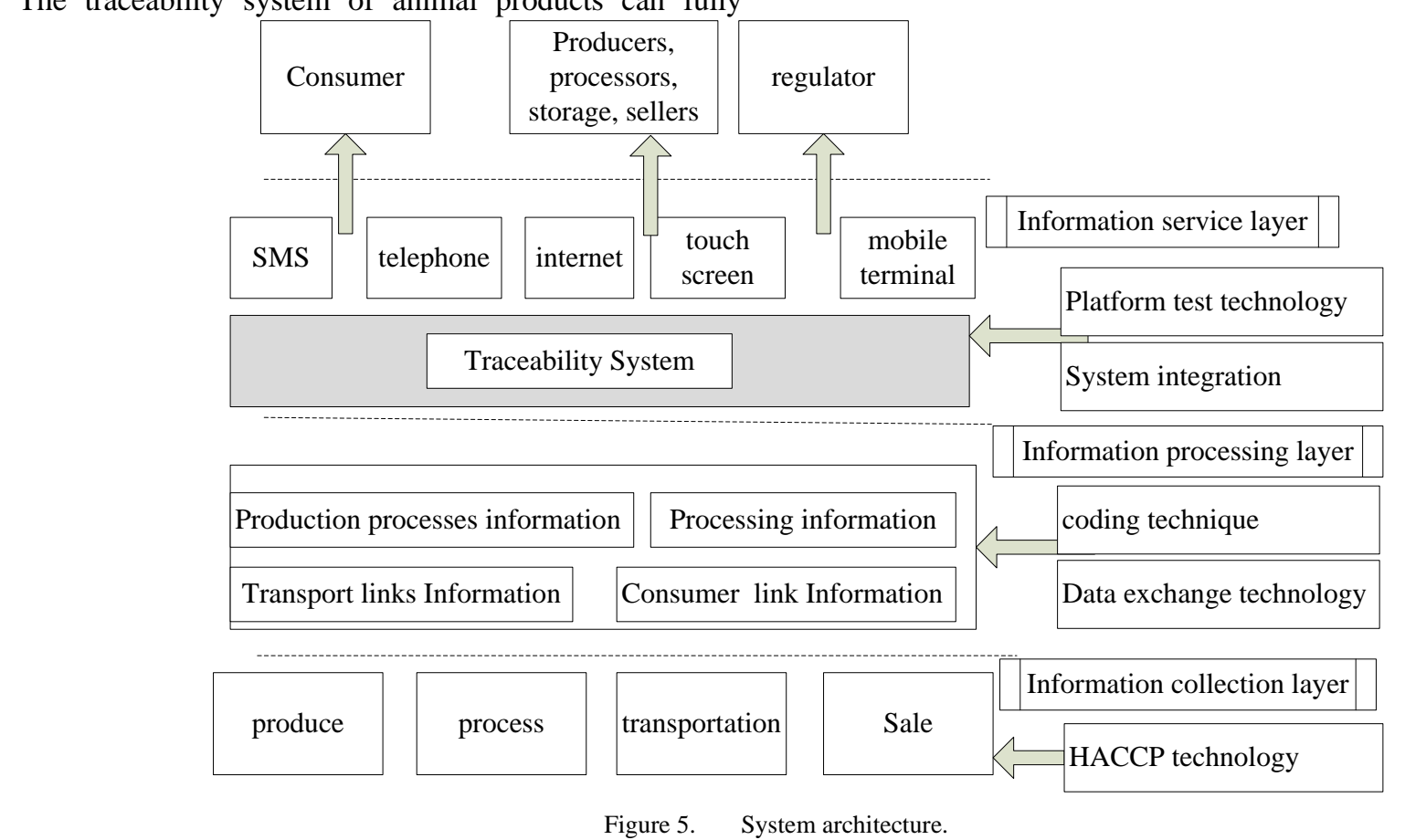

Figure 5. System architecture. cover the food supply chain links such as raw material production, product processing, storage and transportation, marketing and so on. The traceability system of animal products can be decomposed from three layers: information collection, information processing and information service. The overall architecture design of the system is shown in fig. 5.
At the information collection level, analyze the entire chain, including all aspects of business processes. Based on the principle and method of HACCP, the quality safety factors and the key control points of each link in the food traceability chain are studied. Design the food safety traceability chain encoding system using national and industry related encoding standards.

At the information processing level, we can obtain the relevant information on food traceability chain by using information collection, data exchange and other technologies. Construct information management system about food production process, processing, storage and transportation process, consumption process, quality and safety, in order to be science, regulation and orderly.

At the Information services layer, consumers and regulators can query quality and safety information through SMS, telephone, network platform, mobile terminal and other ways.

\section{B. System Function Frame Design}

The establishment of traceability system can realize the information transparency of all links in the supply chain of animal products, and ensure the quality and safety of animal products. The overall framework of the traceability system is 
based on the standard system, as shown in fig. 6 .

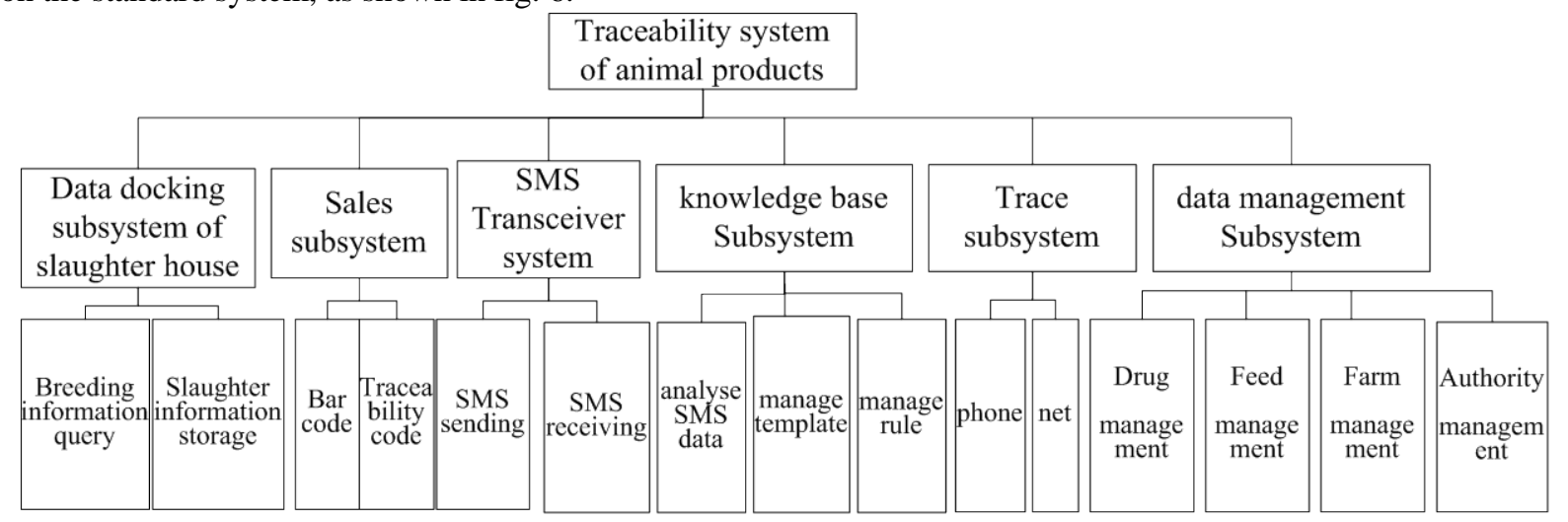

Figure 6. Function framework of traceability system.

Traceability system includes six subsystems: slaughter drovers system, sales system, short message subsystem, knowledge base system, traceability system subsystem and data management subsystem.

SMS subsystem (specifically, farming link) can receive text messages from farmers, including lairage, immune, die Amoy and slaughter. After the system of SMS content data extraction, System feedback to farmers. At the same time, short message system, but also send training information to farmers, to raise the level of farm breeding farms, and promote the healthy development of food safety.

The knowledge base subsystem can improve the accuracy of the data extraction of the short message system. Through the analysis of the content of the text messages, manage SMS template, so that the most effective way of data extraction.

On data docking subsystem of slaughter house, Information docking in the system according to animal products ketone body tag number and ear label of information on the basis of the existing slaughterhouse system.

Traceability subsystem can query the supply chain and sales information of the purchased animal products.

Data management subsystem can manage animal products information throughout the supply chain, including farms registered information, feed information, drug information, and identification of slaughter, transport and sale of part of the conversion information to assure information continuity.

\section{DESIGN OF SOFTWARE SYSTEM FOR TRACEABILITY SYSTEM OF ANIMAL PRODUCTS}

Based on the requirement of system and the characteristic of software system, the C/S software system is adopted in the breeding farm, the slaughter house and the sales department. Because the three systems are using Industrial Modem Wireless (SMS cat) equipment and SMS cat secondary development using C \# language, we are used to encode C \# language and using Visual Studio 2008 IDE for development. Using $\mathrm{B} / \mathrm{S}$ software architecture in management center and information tracing system, and selecting popular, stable JAVA development system SSH2 (Struts2, Spring, Hibernate) framework, using Myeclipse8.5IDE for development. Two software systems achieve the integration of the system through the sharing of data layer. The software architecture of the system is shown in fig. 7.

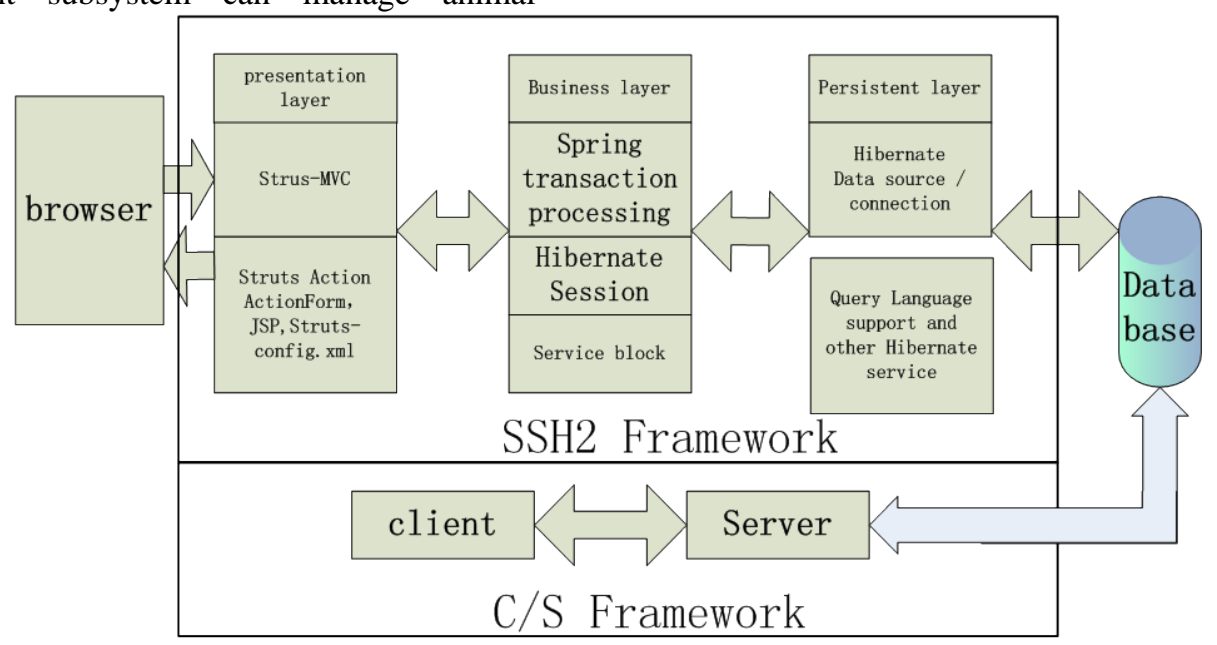

Figure 7. System technical architecture diagram. 


\section{SUMMARY}

This paper carries out structural analysis on the traceability system of animal products from the three aspects. According to the actual situation, design the combination of $\mathrm{C} / \mathrm{S}$ and $\mathrm{B} / \mathrm{S}$ software system. Through the traceability system of livestock products, we can improve the efficiency of the use of regulatory resources, alleviate the contradiction between the regulatory resources and the task of supervision in the traditional regulatory mode, and form the system in which the government led, industry organizations, producers and consumers and other public multiple subjects to participate in the supervision. Therefore, the full implementation of traceability system in our country is the inevitable trend of the development of food quality and safety.

\section{ACKNOWLEDGMENT}

This research was financially supported by the Provincial key projects (research on the mechanism of food safety conditions and the construction of the platform 2013SZ) and National Natural Science Foundation of China (research on the key technologies of the spatial temporal correlation of motion vehicle in distributed video (61363043)).

\section{REFERENCES}

[1] Y.J. Xue, Y.M. Hu and J.F. Yang:Information transparency framework of agricultural products supply chain [J]. Machine research, (2008), No.2,p.67 - 70

[2] Lv Qing, Gu Shaoping, Yao Guoxian. The current development situation of the United States and its influence on China [J]. Anhui agricultural science, 2008, 36 (5): 2074-2076

[3] Stanley R, Knight C, Bodnar F. Experiences and challenges in the development of an organic HACCP system[J]. NJAS-Wageningen Journal of Life Sciences, 2011, 58(3): 117-121

[4] Notermans S, Gallhoff G, Zwietering M H. Identification of critical control points in the HACCP system with a quantitative effect on the safety of food products[J]. Food Microbiology, 1995, 12: 93-98

[5] Boccas F, Ramanauskas A, Boutrif E, etal. HACCP "train-in-action" program in the Lithuanian dairy industry[J]. Food Control, 2001, 12(3): 149-156

[6] Operation rules of pig slaughter GB/T17236-2008 [S]. China: national standard, 2008 